\title{
Desempenho produtivo de fêmeas leiteiras alimentadas com silagem de milho e concentrado à base de farelo de soja ou farelo de algodão
}

\author{
Stefanie Alvarenga Santos ${ }^{1}$, José Maurício de Souza Campos ${ }^{2}$, Sebastião de Campos \\ Valadares Filho ${ }^{2}$, Edenio Detmann ${ }^{2}$, André Soares de Oliveira ${ }^{3}$, Shirley Motta de Souza ${ }^{3}$ \\ 1 Doutorando em Zootecnia - UFV. Bolsita da FAPEMIG. \\ 2 Departamento de Zootecnia - UFV - Bolsista do CNPq. \\ ${ }^{3}$ Doutorando em Zootecnia - UFV.
}

RESUMO - Foram avaliadas dietas com silagem de milho e concentrado à base de farelo de soja ou farelo de algodão para fêmeas leiteiras. Quatro dietas experimentais foram constituídas da combinação de dois níveis de concentrado (1 ou 2 kg) e duas fontes proteicas (farelo de soja ou farelo de algodão). Observou-se efeito da interação nível de concentrado $\times$ fonte proteica no consumo de matéria seca (MS), fibra em detergente neutro (FDN) e no consumo de nutrientes digestíveis totais (NDT). A quantidade de concentrado influenciou os consumos de proteína bruta (PB), FDN, extrato etéreo (EE), carboidratos nãofibrosos (CNF), matéria orgânica (MO) e de PB por kg de NDT. Não houve efeito nas digestibilidades da MS, FDN, MO e para NDT, porém a fonte proteica influenciou as digestibilidades de PB, EE e CNF. Houve efeito da quantidade de concentrado sobre o ganho de peso (GP) e da interação quantidade de concentrado $\times$ fonte proteica sobre o ganho de peso por cm de ganho em altura da cernelha. A dieta com $1 \mathrm{~kg}$ de concentrado à base de farelo de algodão foi insuficiente para ganho de peso de 800 g/dia, enquanto as dietas com $2 \mathrm{~kg}$ de concentrado propiciaram o maior ganho de peso. Entretanto, a dieta constituída de 2 kg de concentrado à base de farelo de soja foi mais eficiente, pois propiciou maior crescimento linear das novilhas, com ganho médio de 820 g por dia. Equações de predição do peso corporal com base no perímetro torácico apresentam maior acurácia em relação a equações baseadas em outras medidas lineares.

Palavras-chave: consumo, energia, novilhas leiteiras, proteína

\section{Productive performance of growing dairy heifers fed corn silage and soybean or cottonseed meal based concentrate}

\begin{abstract}
Diets for dairy heifers were assessed with corn silage and soybean or cotton seed based concentrate. Four experimental diets consisting of the combination of two concentrate levels, 1 or $2 \mathrm{~kg}$, and two protein sources, soybean meal or cotton seed meal. The effect of the interaction was observed for intake of dry matter (DM), neutral detergent fiber (NDF) in \% live weight and total digestible nutrient intake (TDN). The quantity of concentrate influenced the intakes of crude protein (CP), NDF, ether extract (EE), non-fibrous carbohydrates (NFC), organic matter (OM) and CP per kg TDN. There was no significant effect of the treatments for DM, NDF, OM and NDT digestibility but the protein source influenced the CP, EE and NFC digestibility. There was an effect of concentrate quantity for weight gain (WG), and there was effect of the concentrate quantity $\times$ protein source interaction for weight gain per $\mathrm{cm}$ of height gain of the cernelha. The diet consisting of $1 \mathrm{~kg}$ cotton seed based concentrate was insufficient to reach $800 \mathrm{~g} /$ day weight gain and diets consisting of $2 \mathrm{~kg}$ concentrate resulted in greater weight gain. However, the diet consisting of $2 \mathrm{~kg}$ soybean meal based concentrate was more efficient because it gave greater linear growth to the heifers with an $820 \mathrm{~g}$ mean gain per day. Body weight prediction equations based on the thorax perimeter are more accurate in prediction compared to the other linear measurements.
\end{abstract}

Key Words: intake, energy, dairy heifers, protein

\section{Introdução}

Diferentes combinações entre volumoso e concentrado podem ser empregadas na alimentação de fêmeas após a desmama e resultam em diferentes taxas de ganho de peso. Como consequência, a idade ao primeiro parto pode variar de 24 até 34 meses ou mais (Campos \& Lizieire, 1998). Na projeção da idade ao primeiro parto para 22 meses, deve-se buscar ganhos de peso superiores a $800 \mathrm{~g} /$ dia e, nesses sistemas, a silagem de milho é o volumoso mais usado para fêmeas leiteiras em crescimento e o concentrado geralmente é constituído de fubá de milho e farelo de soja. A utilização desses ingredientes, no entanto, pode conduzir ao fornecimento inadequado de energia em relação a proteína

Recebido em 29/8/2008 e aprovado em 13/3/2009.

Correspondências devem ser enviadas para: stefanie_zootecnia@hotmail.com 
quando essas dietas são calculadas segundo as exigências de proteína sugeridas pelo NRC (2001), com relação energia:proteína dietética acima das exigências.

Um sério problema do alto consumo de energia nessa fase é o acúmulo de tecido adiposo na glândula mamária, que ocorre no seu período de crescimento alométrico, diminuindo a habilidade de produzir leite no futuro (Sejrsen \& Purup, 1997). Posteriormente, o excesso de gordura corporal pode aumentar a ocorrência de distocia ao parto e outros distúrbios, reduzindo a ingestão de matéria seca (MS) no pós-parto.

Uma possibilidade para reduzir esses problemas seria reduzir a quantidade de concentrado e, com o uso de fontes de elevado teor proteico, à semelhança do farelo de soja, ajustar a relação entre proteína e energia. Entretanto, um dos grandes desafios para atender às exigências de proteína em ruminantes é substituir esse farelo por fontes proteicas alternativas, uma vez que a nutrição desses animais conta com forte concorrência pelo uso deste insumo, seja na nutrição de monogástricos seja para produção de biocombustíveis.

Em decorrência dos entraves no fornecimento de silagem de milho e concentrado-padrão, à base de farelo de soja e fubá de milho, para atender exigências de proteína em relação a energia, objetivou-se com este trabalho avaliar dois níveis de fornecimento de concentrado com farelo de algodão em substituição ao farelo de soja como principal fonte proteica na dieta de fêmeas leiteiras em crescimento.

\section{Material e Métodos}

O experimento foi realizado no Laboratório de Animais do Departamento de Zootecnia da Universidade Federal de Viçosa entre março e junho de 2006. Foram utilizadas 28 novilhas mestiças Holandês-Zebu, com aproximadamente 10 meses de idade e peso inicial médio de $180 \mathrm{~kg}$, distribuídas em delineamento de blocos casualizados, com sete repetições, considerando cada animal uma unidade experimental e com os blocos formados de acordo com o peso inicial dos animais. As novilhas foram alojadas em baias individuais (3×5 m), com solários, comedouros e bebedouros individuais.

Os quatro tratamentos experimentais foram constituídos da combinação de dois níveis de concentrado (1 ou $2 \mathrm{~kg}$ ) e duas fontes proteicas (farelo de soja ou farelo de algodão), em esquema fatorial $2 \times 2$. Nas rações concentradas fornecidas no nível de $2 \mathrm{~kg}$, utilizou-se farelo de trigo para que as dietas fossem isonitrogenadas (Tabela 1). O volumoso, silagem de milho, foi oferecido à vontade, em quantidade suficiente para que ocorressem sobras de até $10 \%$ do fornecido em matéria natural.
Tabela 1 - Composição dos concentrados e das dietas (\%MS)

\begin{tabular}{|c|c|c|c|c|}
\hline \multirow{3}{*}{$\begin{array}{l}\text { Item } \\
\text { Ingrediente }\end{array}$} & \multicolumn{4}{|c|}{ Concentrado } \\
\hline & \multicolumn{2}{|c|}{$\begin{array}{l}\text { Farelo } \\
\text { de soja }\end{array}$} & \multicolumn{2}{|c|}{$\begin{array}{c}\text { Farelo } \\
\text { de algodão }\end{array}$} \\
\hline & $1 \mathrm{~kg}$ & $2 \mathrm{~kg}$ & $1 \mathrm{~kg}$ & $2 \mathrm{~kg}$ \\
\hline Farelo de soja & 93,14 & 28,57 & 0,00 & 0,00 \\
\hline Farelo de algodão (38\% PB) & 0,00 & 0,00 & 90,29 & 28,57 \\
\hline Farelo de trigo & 0,00 & 67,60 & 0,00 & 66,83 \\
\hline Ureia/Sulfato amônio (9:1) & 2,23 & 1,51 & 5,09 & 2,29 \\
\hline \multirow[t]{2}{*}{ Mistura mineral } & 4,63 & 2,31 & 4,63 & 2,31 \\
\hline & \multicolumn{4}{|c|}{ Dieta } \\
\hline Silagem de milho & 82,5 & 65,0 & 82,5 & 65,0 \\
\hline Farelo de soja & 16,3 & 10,0 & 0,00 & 0,00 \\
\hline Farelo de algodão (38\% PB) & 0,00 & 0,00 & 15,8 & 10,0 \\
\hline Farelo de trigo & 0,00 & 23,66 & 0,0 & 23,39 \\
\hline Ureia/ Sulfato amônio (9:1) & 0,39 & 0,53 & 0,89 & 0,80 \\
\hline Mistura mineral ${ }^{1}$ & 0,81 & 0,81 & 0,81 & 0,81 \\
\hline \multicolumn{5}{|l|}{ Composição nutricional } \\
\hline Matéria seca & 34,69 & 42,34 & 35,13 & 42,54 \\
\hline Matéria orgânica & 94,03 & 92,74 & 93,38 & 92,56 \\
\hline Proteína bruta & 13,64 & 13,57 & 13,98 & 13,81 \\
\hline Nitrogênio não-proteico (NNP) & 50,47 & 47,72 & 50,46 & 48,10 \\
\hline NIDN (\%NNP) & 26,27 & 26,31 & 26,11 & 26,32 \\
\hline NIDA (\%NNP) & 8,91 & 8,11 & 8,84 & 8,16 \\
\hline Extrato etéreo & 2,84 & 3,02 & 2,91 & 3,07 \\
\hline Carbohidratos totais & 78,18 & 77,01 & 77,94 & 72,98 \\
\hline Carboidratos não-fibrosos & 28,47 & 27,29 & 25,81 & 24,75 \\
\hline Fibra em detergente neutro & 49,71 & 49,72 & 52,13 & 52,23 \\
\hline FDNcp & 44,06 & 43,96 & 46,38 & 46,42 \\
\hline $\mathrm{FDNi}$ & 16,03 & 15,41 & 17,72 & 16,87 \\
\hline Fibra em detergene ácido & 26,70 & 25,97 & 28,05 & 26,69 \\
\hline $\begin{array}{l}\text { Fibra em detergente } \\
\text { ácido indigestível }\end{array}$ & 12,47 & 11,98 & 14,01 & 12,80 \\
\hline Lignina & 4,75 & 4,81 & 5,58 & 5,37 \\
\hline Lignina/FDN & 9,55 & 9,67 & 10,70 & 10,28 \\
\hline
\end{tabular}

O experimento foi composto de 14 dias de adaptação às dietas e três períodos experimentais de 28 dias, perfazendo um total de 84 dias de experimento para a coleta de dados e avaliação do desenvolvimento dos animais. No início e no final do experimento, após jejum de sólidos de 14 horas, os animais foram submetidos à pesagem individual e medições do perímentro torácico, altura da cernelha e da garupa e comprimento do corpo. As mensurações foram feitas segundo metodologia de Hoffman (1997), com os animais em estação forçada, isto é, membros anteriores e posteriores na perpendicular sobre um piso plano, formando um paralelogramo retangular.

Foram feitas avaliações das equações de predição do peso corporal (PV) propostas por Heinrichs et al. (1992), com base nas variáveis perímetro torácico (PT), altura da cernelha (AC) e comprimento do corpo (CC), denominadas respectivamente: $\mathrm{H} 1\left(\mathrm{PV}=102,71-2,876 \mathrm{PT}+0,02655 \mathrm{PT}^{2}\right)$, H2 $\left(\mathrm{PV}=632,13-16,837 \mathrm{AC}+0,11989 \mathrm{AC}^{2}\right)$ e H3 $(\mathrm{PV}=96$ $\left.-3,24 \mathrm{CC}+0,03432 \mathrm{CC}^{2}\right)$, outras duas propostas por Reis 
et al. (2004), baseadas no perímetro torácico e na altura da garupa (AG), denominadas R1 (PV = $1717-35,167 \mathrm{PT}+$ $\left.0,23897 \mathrm{PT}^{2}-0,0004626 \mathrm{PT}^{3}\right)$ e R2 $(\mathrm{PV}=7581-4,151 \mathrm{PT}-$ $180,201 \mathrm{AG}+0,024932 \mathrm{PT}^{2}+1,456103 \mathrm{AG}^{2}-0,00383079$ $\left.\mathrm{AG}^{3}\right)$, e da equação de Quetelet, denominada Q1 (PV=PT 2 x 0,9CC) apresentada por Jardim (1973).

Todas as equações foram baseadas na relação dos valores observados e preditos, por meio de ajustamento de regressão linear simples dos valores preditos sobre os observados, de modo que as estimativas dos parâmetros da regressão foram testadas pelo teste $\mathrm{F}$ e sob as seguintes hipóteses (Mayer et al., 1994):

Ho: $\beta_{0}=0$ e $\beta_{1}=1$

Ha: não Ho

Somente no caso de não-rejeição de Ho, concluiu-se que o modelo predisse com acurácia os valores observados. Os procedimentos estatísticos descritos para construção e validação do modelo foram realizados por meio do programa Statistical Analysis System - SAS, adotando-se 0,05 como nível crítico de probabilidade para o erro tipo I.

A identificação da eficiência de predição das equações foi feita pela avaliação e decomposição do quadrado médio do erro de predição, segundo protocolo descrito por Kobayashi \& Salam (2000), conforme as equações: $\mathrm{QMEP}=\mathrm{QV}+\mathrm{MaF}+\mathrm{MoF} ; \mathrm{QV}=(\mathrm{X}-\mathrm{Y})^{2}$; $\mathrm{MaF}=(\mathrm{SDx}-\mathrm{SDy}) ; \mathrm{MoF}=2 \cdot \mathrm{SDx} \cdot \mathrm{SDy} \cdot(1-\mathrm{r})$; em que: $\mathrm{QMPE}=$ quadrado médio do erro de predição; $\mathrm{QV}=$ quadrado do vício; $\mathrm{MaF}=$ magnitude de flutuação aleatória; $\mathrm{MoF}$ = modelo de flutuação; $\mathrm{X}=$ média dos valores preditos; $\mathrm{Y}$ = média dos valores observados; $\mathrm{SDx}$ e SDy = desvio-padrão para os valores preditos e observados, respectivamente; e $r$ = correlação linear de Pearson entre valores preditos e observados.

As pesagens dos alimentos fornecidos e das sobras de cada animal para avaliação do consumo foram diariamente acompanhadas de amostragens dos alimentos e das sobras. As amostras foram acondicionadas em sacos plásticos e congeladas para posteriores análises e, a cada sete dias, foram descongeladas, secas em estula de ventilação forçada ( $60^{\circ} \mathrm{C} / 72$ horas) e trituradas em moinho de facas ( $1 \mathrm{~mm}$ ) para realização de amostras compostas para cada período.

No segundo período experimental, foi realizada a coleta

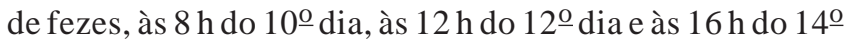
dia, diretamente do reto dos animais. As amostras foram acondicionadas em sacos plásticos e congeladas $\left(-20^{\circ} \mathrm{C}\right)$ e, ao final do período de coletas, foram secas, moídas e constituíram amostras composta por animal, com base no peso seco ao ar. Também foram retiradas amostras de sobras e alimentos fornecidos durante esse período de coleta de fezes.
A estimativa da excreção fecal foi feita utilizando-se fibra em detergente neutro indigestível (FDNi) como indicador interno. Neste procedimento as amostras de alimentos, sobras e fezes foram colocadas em sacos de digestibilidade Ankon (Filter bag F57), incubadas no rúmen de um animal mestiço fistulado mantido com dieta à base de silagem de milho e concentrado por um período de 264 horas. O material remanescente da incubação foi previamente lavado com água e submetido à extração com detergente neutro, de modo que o resíduo foi considerado FDNi.

As análises de matéria seca (MS), matéria orgânica (MO), matéria mineral (MM), proteína bruta (PB), nitrogênio insolúvel em detergente neutro (NIDN), nitrogênio insolúvel em detergente ácido (NIDA), extrato etéreo (EE), fibra em detergente neutro corrigido para cinza e proteína $\left(\mathrm{FDN}_{\mathrm{Cp}}\right)$, fibra em detergente ácido (FDA) e lignina $\mathrm{H}_{2} \mathrm{SO}_{4} 72 \% \mathrm{p} / \mathrm{p}$ seguiram as especificações descritas por Silva \& Queiroz (2002). A determinação de nitrogênio não-proteico (NNP) dos alimentos foi realizada segundo Licitra et al. (1996). Os carboidratos totais (CT) foram calculados segundo Sniffen et al. (1992), em que: CT = $100-(\%$ de PB + \% de EE + \% de cinzas), e os carboidratos não-fibrosos corrigidos para cinzas e proteína (CNF), como proposto por Hall (2000): $\mathrm{CNF}=100-((\% \mathrm{~PB}-\%$ PBureia $+\%$ ureia $)+\%$ FDN $+\%$ EE $+\%$ cinzas).

Os dados obtidos foram submetidos à análise de variância e, quando significativos no teste F, foram comparados pelo teste Tukey a 5\% utilizando-se o programa SAEG, versão 7.1(UFV, 1997).

\section{Resultados e Discussão}

Houve efeito $(\mathrm{P}<0,05)$ da interação nível de concentrado $\times$ fonte proteica para consumo de matéria seca (Tabela 2). Os animais que consumiram $1 \mathrm{~kg}$ de concentrado à base de farelo de algodão apresentaram menor consumo de MS em kg/dia e em \%PV (Tabela 3), o que pode estar relacionado à menor aceitabilidade do farelo de algodão mais ureia quando fornecidos unicamente como concentrado. A adição de farelo de trigo, quando fornecidos $2 \mathrm{~kg}$ de concentrado, parece ter diluído esse efeito e seu consumo não diferiu do obtido com o concentrado contendo farelo de soja.

Segundo Van Soest (1994), fatores como a preferência animal, podem determinar a escolha e seleção dos alimentos pelos animais, com base no sabor e na cor.

Brown (1993), utilizando machos de origem leiteira em crescimento, avaliou a suplementação proteica e energética de um feno de baixa qualidade amonizado. Assim como 
Tabela 2 - Consumos diários de nutrientes em fêmeas leiteiras em crescimento alimentadas com silagem de milho e concentrado com farelo de soja ou farelo de algodão

\begin{tabular}{|c|c|c|c|c|c|c|c|c|}
\hline \multirow[b]{3}{*}{ Item } & \multicolumn{4}{|c|}{ Fonte proteica } & \multirow[b]{3}{*}{$\% \mathrm{CV}$} & \multirow{2}{*}{\multicolumn{3}{|c|}{ Efeito }} \\
\hline & \multicolumn{2}{|c|}{ Farelo de soja } & \multicolumn{2}{|c|}{ Farelo de algodão } & & & & \\
\hline & $1 \mathrm{~kg}$ & $2 \mathrm{~kg}$ & $1 \mathrm{~kg}$ & $2 \mathrm{~kg}$ & & FP & Q & $\mathrm{FP} \times \mathrm{Q}$ \\
\hline Matéria seca & 5,90 & 6,20 & 5,57 & 6,46 & 7,2 & ns & $*$ & * \\
\hline Matéria seca (\%PV) & 2,90 & 2,91 & 2,80 & 3,12 & 5,1 & ns & $*$ & $*$ \\
\hline Matéria orgânica & 5,42 & 5,73 & 5,01 & 5,93 & 8,9 & ns & $*$ & ns \\
\hline Proteína bruta & 0,75 & 0,78 & 0,72 & 0,79 & 5,3 & ns & $*$ & ns \\
\hline Fibra em detergente neutro & 2,39 & 2,72 & 2,29 & 2,89 & 9,8 & ns & $*$ & ns \\
\hline Fibra em detergente neutro (\%PV) & 1,26 & 1,24 & 1,28 & 1,42 & 5,7 & $*$ & $*$ & $*$ \\
\hline Extrato etéreo & 0,168 & 0,186 & 0,161 & 0,197 & 8,7 & ns & $*$ & ns \\
\hline Carboidratos não-fibrosos & 2,01 & 2,13 & 1,95 & 2,20 & 7,1 & ns & $*$ & ns \\
\hline Nutrientes digestíveis totais & 4,30 & 4,57 & 3,91 & 4,92 & 7,1 & ns & $*$ & $*$ \\
\hline gPB/kgNDT & 182 & 171 & 194 & 168 & 9,27 & ns & $*$ & ns \\
\hline
\end{tabular}

ns: não-significativo; * $(\mathrm{P}<0,05)$ pelo teste de tukey.

Tabela 3 - Consumos de matéria seca, fibra em detergente neutro e nutrientes digestíveis totais em fêmeas leiteiras em crescimento alimentadas com silagem de milho e concentrado contendo farelo de soja ou farelo de algodão

\begin{tabular}{|c|c|c|c|c|c|c|c|c|}
\hline \multirow[b]{3}{*}{ Fonte protéica } & \multicolumn{8}{|c|}{ Quantidade } \\
\hline & \multicolumn{2}{|c|}{ Matéria seca (kg) } & \multicolumn{2}{|c|}{ Matéria seca (\%PV) } & \multicolumn{2}{|c|}{$\begin{array}{l}\text { Fibra em (\%PV) } \\
\text { detergente neutro }\end{array}$} & \multicolumn{2}{|c|}{$\begin{array}{c}\text { Nutrientes digestíveis } \\
\text { totais }(\mathrm{kg})\end{array}$} \\
\hline & $1 \mathrm{~kg}$ & $2 \mathrm{~kg}$ & $1 \mathrm{~kg}$ & $2 \mathrm{~kg}$ & $1 \mathrm{~kg}$ & $2 \mathrm{~kg}$ & $1 \mathrm{~kg}$ & $2 \mathrm{~kg}$ \\
\hline Farelo de soja & 5,90Aa & $6,20 \mathrm{Aa}$ & $2,90 \mathrm{Aa}$ & 2,91Aa & $1,26 \mathrm{Aa}$ & $1,24 \mathrm{Ab}$ & $4,30 \mathrm{Aa}$ & $4,57 \mathrm{Aa}$ \\
\hline Farelo de algodão & $5,57 \mathrm{Bb}$ & 6,46Aa & $2,80 \mathrm{Bb}$ & $3,12 \mathrm{Aa}$ & $1,28 \mathrm{Ba}$ & $1,42 \mathrm{Aa}$ & $3,91 \mathrm{Ba}$ & 4,92Aa \\
\hline
\end{tabular}

\#Médias seguidas por uma mesma letra maiúscula/minúscula não diferem na linha/coluna pelo teste Tukey a 5\%.

nesta pesquisa, a adição da fonte energética (melaço) ao suplemento aumentou o consumo de $5,7 \mathrm{~kg}$ MS/dia para 6,8 kg MS/dia, comprovando que o farelo de algodão administrado como suplemento único pode ter menor aceitabilidade pelos animais. Zin et al. (1997), também trabalhando com machos em crescimento, não observaram diferenças significativas no consumo de matéria seca quando adicionaram até $32 \%$ de farelo de algodão em dietas à base de feno de alfafa e milho extrusado, o que indica que o efeito diluidor da baixa palatabilidade do farelo de algodão deve ser considerado.

Mesmo assim, os animais que consumiram a dieta com $1 \mathrm{~kg}$ de farelo de algodão apresentaram consumo de $5,57 \mathrm{~kg}$ de MS/dia ou 2,80\% do PV, ou seja, correspondente ao preconizado pelo NRC (2001), que é de 5,6 kg/dia para animais com média de 220 kg e ganho diário médio (GDM) de 800 g. Esses valores também estão de acordo com o trabalho de Quigley et al. (1986a), que estabeleceram equações para predizer o consumo de matéria seca de fêmeas em sistema intensivo de manejo. Para o mesmo ganho médio diário e peso médio, encontraram consumo diário de matéria seca de 5,6 kg/dia.

Para o consumo de proteína bruta, houve efeito $(\mathrm{P}<0,05)$ apenas da quantidade de concentrado. Provavelmente, o consumo de proteína bruta acompanhou o padrão de consumo de matéria seca, que também sofreu efeito da quantidade de concentrado. Os animais que consumiram $2 \mathrm{~kg}$ apresentaram maior consumo de matéria seca, e consequentemente maior consumo de proteína bruta, uma vez que as dietas foram isonitrogenadas. A observação de Quigley et al. (1986b) parece justificar esse fato, pois os autores relataram que o aumento na proporção de concentrado nas dietas de novilhas leiteiras geralmente resulta em aumento no consumo quando as dietas são fornecidas à vontade até que as exigências de energia sejam alcançadas. Segundo Amos (1986), em pesquisa com machos e fêmeas de origem leiteira em crescimento consumindo dietas de alta e baixa energia, com a adição de milho e sebo aos concentrados, o consumo de proteína bruta variou diretamente com o consumo de matéria seca. Assim como foi observado neste experimento, Blackwelder et al. (1998) também não encontraram efeito da fonte proteica sobre o consumo de PB quando compararam farelo de soja e farelo de algodão para vacas de alta produção. De acordo com NRC (2001), o consumo de PB médio predito para fêmeas leiteiras em crescimento com peso médio de $220 \mathrm{~kg}$ e ganhando 800 g/dia é de $770 \mathrm{~g} /$ dia, próximo aos dados obtidos neste trabalho.

O consumo de FDN em $\mathrm{kg} /$ dia foi afetado pela quantidade de concentrado $(\mathrm{P}<0,05)$ e foi maior entre os 
animais que consumiram $2 \mathrm{~kg}$ de concentrado. Apesar de os animais que consumiram $1 \mathrm{~kg}$ de concentrado apresentarem maior consumo de silagem, aqueles que receberam $2 \mathrm{~kg}$ ingeriram farelo de trigo, que tem maior teor de FDN, tornando próximos os valores de FDN de todas as dietas (Tabela 1).

Assim, o que influenciou o consumo de FDN foi o consumo de matéria seca, uma vez que animais recebendo $2 \mathrm{~kg}$ de concentrado apresentaram maior consumo de FDN. Segundo Mertens (1992), a FDN é importante na regulação do consumo e na limitação física de consumo da dieta. Entretanto, quando a FDN da dieta está abaixo de 50 a $60 \%$, o consumo não é altamente correlacionado à digestibilidade (Conrad et al., 1964; Ousbourn et al., 1974), o que pode ter ocorrido neste experimento. Desse modo, o consumo é limitado pela demanda energética e as variações associadas às diferenças entre animais reduzem significativamente. Entretanto, segundo Detmann et al. (2003), não há um ponto exato de transição, mas uma faixa em que os fatores físicos e fisiológicos atuam simultaneamente. Quingley et al. (1986b) relataram que teores de FDN próximos de $44 \%$ parecem não limitar o consumo máximo de matéria seca em fêmeas leiteiras em crescimento.

Portanto, neste experimento, o perfil do consumo de FDN em kg/dia acompanhou o consumo de MS, apesar de não ter determinado limitações físicas, o que parece ter ocorrido também para o consumo de FDN em \% do PV, pois houve efeito da interação entre os fatores $(P<0,05)$, uma vez que o consumo de FDN pelos animais que receberam $1 \mathrm{~kg}$ de farelo de algodão foi menor que naqueles que consumiram $2 \mathrm{~kg}$ e esta dieta experimental com $2 \mathrm{~kg}$ de concentrado foi também a que proporcionou o menor consumo de matéria seca. Com o fornecimento de $2 \mathrm{~kg}$ de concentrado, o farelo de algodão proporcionou o maior consumo de FDN, provavelmente em virtude dos altos teores de FDN dos farelos de algodão e trigo neste concentrado.

Os consumos de EE, CNF e MO parecem seguir o comportamento dos outros nutrientes, pois houve efeito somente da quantidade de concentrado $(\mathrm{P}<0,05)$. $\mathrm{O}$ maior consumo desses componentes foi observado nos animais que consumiram $2 \mathrm{~kg}$ de concentrado, em virtude do maior consumo de MS para essas dietas. O consumo de NDT foi influenciado pela interação entre os fatores $(P<0,05)$, uma vez que os animais que receberam farelo de algodão consumindo $1 \mathrm{~kg}$ de concentrado apresentaram menor consumo de NDT, o que confirma o efeito do consumo de MS sobre o consumo de todos os nutrientes, sobretudo os nutrientes digestíveis.

De acordo com NRC (2001), o consumo médio de NDT predito para fêmeas leiteiras em crescimento com peso médio de $220 \mathrm{~kg}$ e ganhando $800 \mathrm{~g} /$ dia é de 3,55 kg/dia, abaixo da média obtida neste trabalho. É possível atribuir o elevado consumo de NDT à alta qualidade da silagem oferecida. Segundo Obara et al. (1991), colheita, preparação e métodos de conservação são características críticas para qualidade e palatabilidade da silagem e proporcionam alta qualidade, alto conteúdo de nitrogênio e alta digestibilidade, resultando em maior consumo. $\mathrm{O}$ uso de $1 \mathrm{~kg}$ de farelo de algodão parece ter diminuído esse efeito, em razão da maior inclusão de ureia neste concentrado, o que reduziu a palatabilidade.

O consumo de PB por kg de NDT foi afetado de forma significativa pela quantidade de concentrado $(\mathrm{P}<0,05)$, uma vez que os animais que receberam $1 \mathrm{~kg}$ de concentrado apresentaram maior consumo de PB em relação à energia, tendo em vista a maior densidade proteica dos concentrados oferecidos. Os dados obtidos estão um pouco abaixo do recomendado pelo NRC (1989; 2001), que apresenta valores em torno de 207 a 217 g PB por kg de NDT, para manter saudável o crescimento e desenvolvimento da glândula mamária de fêmeas nesta fase. Esse baixo consumo de PB em relação à energia pode ser consequência do elevado consumo de NDT.

Não houve efeito significativo de nenhum fator sobre os coeficientes de digestibildade de matéria seca, da fibra em detergente neutro e dos nutrientes digestíveis totais (Tabela 4). Esses parâmetros parecem ser bastante correlacionados. Segundo Van Soest (1994), a digestibilidade da MS e da MO depende do teor de parede celular e sua disponibilidade para digestão, determinada pelo grau de lignificação e outros fatores. Quanto maior o teor de lignina, maior a relação do consumo com a digestibilidade. Desta forma, as digestibilidades desses componentes não foram afetadas, uma vez que não houve diferenças notáveis na relação lignina/FDN entre as dietas. Crampton et al. (1960) atribuíram as variações no desempenho animal ao consumo e à digestibilidade, numa proporção de 70:30, ou seja, o consumo é a variável de maior importância, enquanto a digestibilidade é um fator secundário.

Uma vez que a parede celular tem efeito sobre a interação enchimento $\times$ distensão ruminal, a taxa de fermentação depende das propriedades intrínsecas dos carboidratos, antes mesmo da lignificação. Neste experimento, a alta qualidade da fibra parece não ter limitado o consumo.

Brown (1993), em pesquisa sobre suplementação proteica com farelo de algodão fornecido na forma exclusiva ou adicionado de melaço para machos em crescimento, também não encontrou variações nas digestibilidades da MO e da FDN. Cardoso et al. (2000), Carvalho et al. (1997) e Berchielli (1994) testaram níveis de concentrado na dieta 
Tabela 4 - Digestibilidade aparente de nutrientes em fêmeas leiteiras em crescimento alimentadas com silagem de milho e concentrado contendo farelo de soja ou farelo de algodão

\begin{tabular}{|c|c|c|c|c|c|c|c|c|}
\hline \multirow{3}{*}{$\begin{array}{l}\text { Item } \\
\text { Coeficiente de digestibilidade (\%) }\end{array}$} & \multicolumn{4}{|c|}{ Fonte proteica } & \multirow[b]{3}{*}{$\% \mathrm{CV}$} & \multirow{2}{*}{\multicolumn{3}{|c|}{ Efeito }} \\
\hline & \multicolumn{2}{|c|}{ Farelo de soja } & \multicolumn{2}{|c|}{ Farelo de algodão } & & & & \\
\hline & $1 \mathrm{~kg}$ & $2 \mathrm{~kg}$ & $1 \mathrm{~kg}$ & $2 \mathrm{~kg}$ & & FP & $\mathrm{Q}$ & $\mathrm{FP} \times \mathrm{Q}$ \\
\hline Matéria seca & 74,93 & 72,94 & 74,40 & 72,05 & 3,8 & ns & ns & ns \\
\hline Proteína bruta & 81,53 & 77,24 & 75,41 & 78,10 & 8,1 & $*$ & ns & ns \\
\hline Fibra em detergente neutro & 61,07 & 60,07 & 58,67 & 61,21 & 9,4 & ns & ns & ns \\
\hline Extrato etéreo & 95,14 & 91,35 & 93,13 & 92,14 & 2,1 & $*$ & ns & ns \\
\hline Carboidratos não-fibrosos & 93,38 & 94,41 & 85,82 & 90,5 & 11,9 & * & ns & ns \\
\hline Matéria orgânica & 75,96 & 74,59 & 75,79 & 75,79 & 4,9 & ns & ns & ns \\
\hline Nutrientes digestíveis totais & 74,56 & 72,40 & 71,12 & 74,56 & 7,0 & ns & ns & ns \\
\hline
\end{tabular}

ns: não-significativo; * $(\mathrm{P}<0,05)$ pelo teste Tukey.

de novilhos mestiços e encontraram resposta linear crescente para as digestibilidades de matéria seca e matéria orgânica, que atribuíram à maior presença de carboidratos não-fibrosos nas dietas com maior porcentagem de concentrado. Todavia, isso não ocorreu neste experimento, uma vez que as dietas com maior nível de concentrado foram formuladas com farelo de trigo, um ingrediente com alto teor de FDN, o que parece ter compensado a menor relação volumoso:concentrado destas dietas e acarretado menor consumo de FDN oriunda da forragem basal, equiparando assim a digestibilidade da FDN de todas as dietas, em decorrência da alta digestibilidade da silagem fornecida.

Houve efeito significativo da fonte proteica $(\mathrm{P}<0,05)$ sobre as digestibilidades de PB, EE e CNF, uma vez que o farelo de soja proporcionou maior digestibilidade desses nutrientes. Grings et al. (1991) relataram que a maior parte da proteína do farelo de algodão é lentamente degradada no rúmen. Maesoomi et al. (2006), comparando o farelo de algodão ao farelo de canola para vacas em lactação, verificaram que o coeficiente de digestibilidade da PB do farelo de algodão foi inferior ao do farelo de canola e atribuíram esse resultado à taxa de degradação desse ingrediente, que é de moderada à lenta, ao contrário do farelo de canola, que possui perfil de degradação próximo ao do farelo de soja. Pina et al. (2006), comparando o farelo de algodão ao farelo de soja, também encontraram menor coeficiente de digestibilidade da proteína para as dietas à base de farelo de algodão. Assim, a maior digestibilidade da proteína das dietas à base de farelo de soja pode ser atribuída à maior rapidez na sua degradação, afirmativa confirmada pelos dados de Blackwelder et al. (1998), que observaram que o farelo de algodão possui maiores teores de FDA e lignina e sua proteína, menor taxa de degradação em comparação ao farelo de soja.

O extrato etéreo e os carboidratos não-fibrosos das dietas com farelo de soja $(\mathrm{P}<0,05)$ apresentaram maiores coeficientes de digestibilidade, uma vez que são nutrientes de rápida degradação e sua taxa de degradação parece ter acompanhado à do farelo de soja, que é maior que a do farelo de algodão (Valadares Filho et al., 2006).

Houve efeito da quantidade de concentrado para todas as características de ganho de peso $(\mathrm{P}<0,05)$. Para o ganho de peso por centímetro de altura de cernelha, houve efeito da interação entre os fatores $(P<0,05)$, pois o fornecimento de $2 \mathrm{~kg}$ de concentrado à base de farelo de soja proporcionou o menor ganho de peso nessa relação (Tabela 5).

O ganho de peso dos animais parece estar relacionado ao consumo de MS, que foi foi maior nos animais que receberem $2 \mathrm{~kg}$ de concentrado. Segundo Crampton et al. (1960), 70\% da variação no desempenho animal pode ser

Tabela 5 - Ganho de peso, perímetro torácico e altura da cernelha em fêmeas leiteiras em crescimento alimentadas com silagem de milho e concentrado contendo farelo de soja ou farelo de algodão

\begin{tabular}{|c|c|c|c|c|c|c|c|c|}
\hline \multirow[b]{3}{*}{ Item } & \multicolumn{4}{|c|}{ Fonte proteica } & \multirow[b]{3}{*}{$\% \mathrm{CV}$} & \multirow{2}{*}{\multicolumn{3}{|c|}{ Efeito }} \\
\hline & \multicolumn{2}{|c|}{ Farelo de soja } & \multicolumn{2}{|c|}{ Farelo de algodão } & & & & \\
\hline & $1 \mathrm{~kg}$ & $2 \mathrm{~kg}$ & $1 \mathrm{~kg}$ & $2 \mathrm{~kg}$ & & FP & $\mathrm{Q}$ & $\mathrm{FP} \times \mathrm{Q}$ \\
\hline Ganho de peso (kg/dia) & 0,78 & 0,82 & 0,69 & 0,91 & 13,4 & ns & $*$ & ns \\
\hline $\begin{array}{l}\text { Ganho de peso (por cm de } \\
\text { altura de cernelha) }\end{array}$ & 15,82 & 8,32 & 11,36 & 12,57 & 22,4 & ns & $*$ & $*$ \\
\hline Perímetro torácico (cm) & 15,12 & 17,40 & 12,16 & 16,80 & 12,2 & ns & $*$ & ns \\
\hline Altura de cernelha $(\mathrm{cm})$ & 4,20 & 8,60 & 5,10 & 6,10 & 21,5 & ns & $*$ & $*$ \\
\hline
\end{tabular}

ns: não-significativo; * $(\mathrm{P}<0,05)$ pelo teste de tukey. 
condicionada pelo consumo, o que parece ter ocorrido neste experimento. Provavelmente, os maiores consumos de NDT e PB foram determinantes da diferença no ganho de peso dos animais.

Os elevados consumos de matéria seca em relação às exigências preditas pelo NRC (2001), provavelmente em razão da elevada qualidade do volumoso oferecido, provocaram elevados ganhos de peso em relação ao ganho em altura de cernelha, acima do recomendado pela Associação Brasileira de Gado Holandês, de $6 \mathrm{~kg}$ por cm de ganho em altura de cernelha, o que pode ser indicativo de acúmulo de gordura corporal e mamária. Além disso, o menor consumo de PB em relação ao NDT (Tabela 4), em comparação ao recomendado pelo NRC (2001), pode ter contribuído para esse padrão de crescimento. Os animais que receberam $2 \mathrm{~kg}$ de concentrado à base de farelo de soja apresentaram o menor valor para este parâmetro $(\mathrm{P}<0,05)$, ou seja, maior equilíbrio do ganho de peso em relação ao crescimento linear.

Valor próximo ao obtido neste experimento para animais consumindo farelo de algodão foi encontrado por Brown (1993), 760 g/dia, em pesquisa com machos em crescimento consumindo concentrado à base de farelo de algodão unicamente ou com adição de melaço. Lanna et al. (1998), também trabalhando com machos e dois níveis de concentrado ( 25 e 45\%) e cana hidrolisada como volumoso, obtiveram aumento significativo no consumo e ganho de peso, 760 g/dia, com o aumento na adição de concentrado à dieta.

Houve efeito da quantidade de concentrado para perímetro torácico $(\mathrm{P}<0,05)$, pois os animais que consumiram $2 \mathrm{~kg}$ de concentrado apresentaram maior crescimento, seguindo o padrão de ganho de peso. Entretanto, houve efeito $(\mathrm{P}<0,05)$ da interação para altura de cernelha. Não houve efeito das quantidades de concentrado quando se utilizou farelo de algodão (Tabela 6), entretanto, quando utilizado farelo de soja, o níveld e $2 \mathrm{~kg}$ de concentrado proporcionou maior crescimento, o que contribuiu significativamente para o crescimento mais uniforme dos animais alimentados com esse concentrado. As fontes de proteína não tiveram efeito significativo quando fornecido $1 \mathrm{~kg}$ de concentrado, mas, no nível de $2 \mathrm{~kg}$, o farelo de soja foi superior, confirmando o maior crescimento em altura de cernelha nesses animais.

Considerando a amplitude dos dados, a avaliação abrangeu toda a fase de crescimento das novilhas neste experimento (Tabela 7). De acordo com a avaliação conjunta do intercepto e do coeficiente de inclinação da equação de regressão dos valores de peso corporal observados sobre os preditos, houve rejeição da hipótese de nulidade $(\mathrm{P}<0,05)$ para todas as equações, o que indica que as equações avaliadas são inadequadas para predição do peso corporal de novilhas leiteiras em crescimento (Tabela 8).

Tabela 6 - Ganho de peso por centímetro de altura da cernelha e altura da cernelha em fêmeas leiteiras em crescimento alimentadas com silagem de milho e concentrado contendo farelo de soja ou farelo de algodão

\begin{tabular}{lccc}
\hline & & & Quantidade \\
\cline { 2 - 3 } Fonte protéica & $1 \mathrm{~kg}$ & $2 \mathrm{~kg}$ & Altura de cernelha \\
\cline { 2 - 4 } & $15,82 \mathrm{Aa}$ & $8,32 \mathrm{Bb}$ & $1 \mathrm{~kg}$ \\
Farelo de soja & $11,36 \mathrm{Ab}$ & $12,67 \mathrm{Aa}$ & $4,20 \mathrm{Ba}$ \\
Farelo de algodão & Ganho de peso por cm altura de cernelha & $5,10 \mathrm{Aa}$ \\
\hline
\end{tabular}

\#Médias seguidas por uma mesma letra maiúscula/minúscula não diferem $(\mathrm{P}<0,05)$ na linha/coluna pelo teste Tukey.

Tabela 7 - Peso corporal observado, perímetro torácico, altura da cernelha, altura da garupa, comprimento do corpo e pesos corporais preditos para fêmeas leiteiras em crescimento

\begin{tabular}{|c|c|c|c|c|c|}
\hline Item & Média & Mínimo & Máximo & Desvio-padrão & $\mathrm{n}$ \\
\hline Peso corporal observado (kg) & 233,0 & 155,0 & 306,0 & 42,1 & 56 \\
\hline H1 (kg) & 219,8 & 139,9 & 305,6 & 44,5 & 56 \\
\hline H2 (kg) & 244,3 & 150,9 & 338,1 & 46,0 & 56 \\
\hline H 3 (kg) & 173,1 & 107,2 & 290,9 & 40,1 & 56 \\
\hline R1 (kg) & 209,4 & 138,9 & 296,1 & 43,5 & 56 \\
\hline R2 (kg) & 202,9 & 135,9 & 280,7 & 41,0 & 56 \\
\hline Q1 (kg) & 215,9 & 145,0 & 302,9 & 43,5 & 56 \\
\hline Perímetro torácico (cm) & 139,3 & 120,0 & 157,0 & 9,8 & 56 \\
\hline Altura de cernelha $(\mathrm{cm})$ & 111,1 & 100,5 & 120,0 & 4,8 & 56 \\
\hline Altura de garupa $(\mathrm{cm})$ & 117,4 & 106,0 & 128,5 & 5,2 & 56 \\
\hline Comprimento do corpo (cm) & 115,7 & 100,1 & 138,0 & 8,6 & 56 \\
\hline
\end{tabular}

Pesos corporais preditos por três equações (H1, H2 e H3) propostas por Heinrichs et al. (1992), duas equações (R1 e R2) propostas por Reis et al. (2004) e outra (Q1) proposta por Jardim (1973). 
Tabela 8 - Regressão associado à hipótese de nulidade conjunta, entre a relação funcional dos valores de peso corporal observados e preditos, para fêmeas leiteiras em crescimento

\begin{tabular}{|c|c|c|c|c|c|c|}
\hline \multirow[t]{3}{*}{ Modelo } & \multicolumn{2}{|c|}{ Descrição média da relação } & \multicolumn{4}{|c|}{ Regressão } \\
\hline & \multirow{2}{*}{$\begin{array}{c}\text { Variável dependente }(\mathrm{Y}) \\
\text { Peso corporalobservado }(\mathrm{kg})\end{array}$} & \multirow{2}{*}{$\begin{array}{l}\text { Variável independente }(\mathrm{X}) \\
\text { Peso corporalpredito }(\mathrm{kg})\end{array}$} & \multicolumn{3}{|c|}{ Estimativa } & \multirow[t]{2}{*}{ Valor $\mathrm{P}^{1}$} \\
\hline & & & $B$ o & $B_{1}$ & $\mathrm{R}^{2}$ & \\
\hline H1 & 233,0 & 219,8 & 26,5754 & 0,9393 & 0,9842 & $<0,0001$ \\
\hline $\mathrm{H} 2$ & 233,0 & 244,3 & 48,7337 & 0,7543 & 0,6779 & $<0,0001$ \\
\hline H3 & 233,0 & 173,1 & 95,0493 & 0,7971 & 0,5739 & $<0,0001$ \\
\hline R1 & 233,0 & 209,4 & 32,0418 & 0,9600 & 0,9814 & $<0,0001$ \\
\hline $\mathrm{R} 2$ & 233,0 & 202,9 & 31,2927 & 0,9944 & 0,9355 & $<0,0001$ \\
\hline Q1 & 233,0 & 215,9 & $-16,780$ & 0,9984 & 0,9356 & $<0,0001$ \\
\hline
\end{tabular}

${ }^{1} H \mathrm{o}: B \mathrm{o}=0$ e $B_{1}=1$.

Pesos corporais preditos por três equações (H1, H2 e H3) propostas por Heinrichs et al. (1992), duas equações (R1 e R2) propostas por Reis et al. (2004) e outra (Q1) proposta por Jardim (1973).

A maioria das equações prediz com alta presença de vício constante, representado pelo quadrado do vício, constituindo-se o principal fator que afetou a qualidade da predição das equações (Tabela 9). Nas equações que utilizam as variáveis altura da cernelha, altura da garupa e comprimento do corpo (H2, H3 e Q1), houve maior contribuição do modelo de flutuação no quadrado médio do erro de predição, o que indica que a direção da predição também é responsável pela baixa qualidade de predição desses modelos.

Observou-se baixa dispersão dos dados de predição a partir do perímetro torácico (Figura 1 a-d), que apresentaram elevada precisão (Figura 1). Entretanto, os dados estão fora da reta dos mínimos quadrados, um pouco acima, o que indica que os modelos subestimam o peso corporal de fêmeas leiteiras em crescimento, em virtude da presença de vício constante.

Além da presença de vícios (Figura 1 e-f), houve elevada dispersão dos dados e erros na direção das curvas, decorrente do elevado modelo de flutuação, o que comprova que os modelos que utilizam o perímetro torácico predizem com maior qualidade os pesos corporais de fêmeas leiteiras em crescimento. Os demais modelos são ineficientes para estas estimativas.
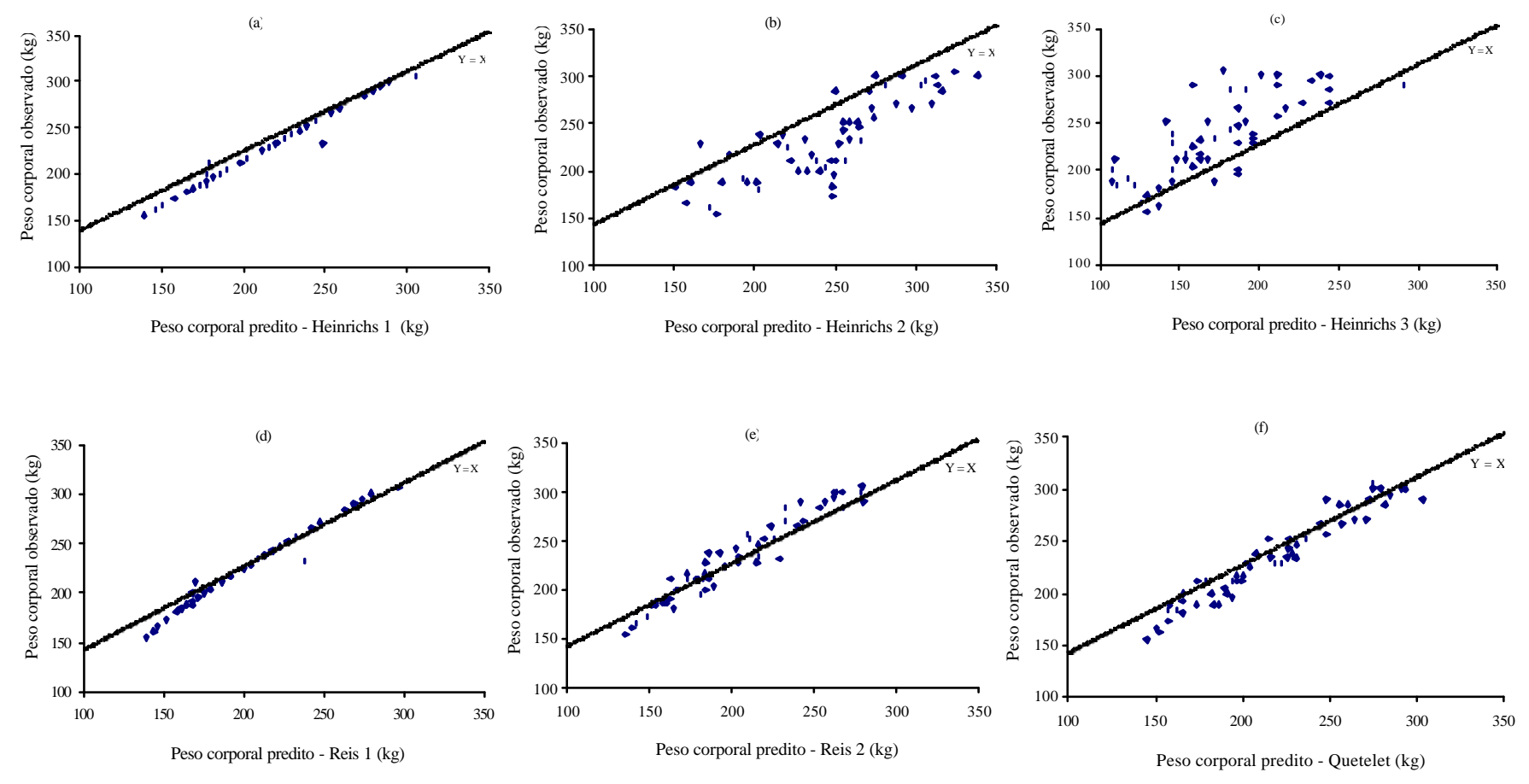

Figura 1 - Curvas de regressãolinear dos pesos corporais preditos pelas equações de Heinrichs et al. (1992), Reis et al. (2004)e Quetelet (f).

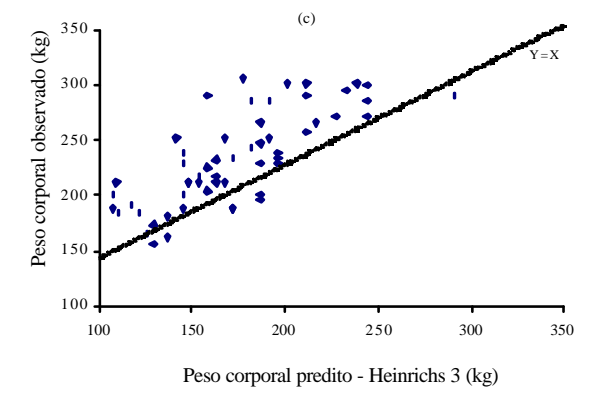


Tabela 9 - Decomposição do quadrado médio do erro de predição (QMEP) em quadrado médio do vício (QV), magnitude de flutuação aleatória (Maf) e modelo de flutuação (Mof), em kg${ }^{2}$ e em valores percentuais, para todas as equações propostas para fêmeas leiteiras em crescimento

\begin{tabular}{|c|c|c|c|c|}
\hline Equação & QMEP & QV & Maf & MoF \\
\hline & \multicolumn{4}{|c|}{$\mathrm{kg}^{2}$} \\
\hline H1 & 210,1 & 175,3 & 5,5 & 29,1 \\
\hline $\mathrm{H} 2$ & 815,2 & 127,80 & 14,8 & 672,5 \\
\hline $\mathrm{H} 3$ & 4398,8 & 3590,7 & 4,4 & 803,8 \\
\hline R1 & 595,6 & 560,1 & 1,8 & 33,7 \\
\hline R2 & 1022,9 & 910,6 & 1,3 & 111,0 \\
\hline \multirow[t]{2}{*}{ Q1 } & 413,7 & 294,1 & 1,8 & 117,8 \\
\hline & \multicolumn{4}{|c|}{$\%$} \\
\hline H1 & 100,0 & 83,5 & 2,6 & 13,9 \\
\hline $\mathrm{H} 2$ & 100,0 & 15,7 & 1,8 & 82,5 \\
\hline $\mathrm{H} 3$ & 100,0 & 81,6 & 0,1 & 18,3 \\
\hline $\mathrm{R} 1$ & 100,0 & 94,0 & 0,3 & 5,7 \\
\hline R2 & 100,0 & 89,0 & 0,1 & 10,9 \\
\hline Q1 & 100,0 & 71,1 & 0,4 & 28,5 \\
\hline
\end{tabular}

Avaliações para três equações (H1, H2 e H3) propostas por Heinrichs et al. (1992), duas equações (R1 e R2) propostas por Reis et al. (2004) e outra (Q1) proposta por Jardim (1973)

\section{Conclusões}

A dieta constituída por $1 \mathrm{~kg}$ de concentrado à base de farelo de algodão é insuficiente para atingir ganho de peso de $800 \mathrm{~g} /$ dia e aquela constituída por $2 \mathrm{~kg}$ de concentrado à base de farelo de soja propicia ganho de peso mais uniforme em relação aos padrões de crescimento desta categoria animal. Equações de predição do peso corporal para fêmeas em crescimento com base no perímetro torácico apresentam maior acurácia de predição em relação a outras medidas lineares.

\section{Referências}

AMOS, H.E. Influence of dietary protein degradability and energy concentration on growth of heifers and steers and intraruminal protein metabolism. Journal of Dairy Science, v.69, p.20992110,1986

BERCHIELLI, T.T. Efeito da relação volumo:concentrado sobre a partição da digestão, a síntese de proteína microbiana, produção de ácidos graxos voláteis e desempenho de novilhos em confinamento. 1994. 104f. Tese (Doutorado em Zootecnia) - Universidade Federal de Minas Gerais, Belo Horizonte.

BLACKWELDER, J.T.; HOPKINS, B.A.; DIAZ, D.E. et al. Milk production and plasma gossypol of cows fed cottonseed and oilseed meals with or without rumen-undergradable protein. Journal of Dairy Science, v.81, p.2934-2941, 1998.

BROWN, W.F. Cane molasses and cottonseed meal supplementation of ammoniated tropical grass hay for yearling cattle. Journal of Animal Science, v.71, p.3451-3457, 1993.

CAMPOS, J.M.S.; ASSIS, A.J. Alimentação de novilhas leiteiras. In: SIMPÓSIO MINEIRO DE NUTRIÇÃO DE GADO DE LEITE, 3., 2005, Belo Horizonte. Anais... Belo Horizonte: UFMG. p. $155-176$.
CAMPOS, O.F.; LIZIEIRE, R.S. Estratégias para obtenção de fêmeas de reposição em rebanhos leiteiros. In: SIMPÓSIO SOBRE PRODUÇÃO ANIMAL, 10., 1998, Piracicaba. Anais... Piracicaba: FEALQ, 1998. p.215-255.

CARDOSO, R.C.; VALADARES FILHO, S.C.; COELHO da SILVA, J.F. et al. Consumo e digestibilidades aparentes totais e parciais de rações contendo diferente níveis de concentrado, em novilhos f1 Limousin $\times$ Nelore. Revista Brasileira de Zootecnia, v.29, p.1832-1843, 2000.

CARVALHO, A.U.; VALADARES FILHO, S.C.; COELHO da SILVA, J.F. et al. Níveis de concentrado em dietas de zebuínos. 1. Consumo e digestibilidade aparente. Revista Brasileira de Zootecnia, v.26, p.986-995, 1997.

CONRAD, H.R.; PRATT, A.D.; HIBBS, J.W. Regulation of feed intake in dairy cows. I. change in importance of physical and physiological factors with increasing digestibility. Journal of Dairy Science, v.47, p.54, 1964.

CRAMPTON, E.W.; DONEFER, E.; LLOYD, L.E. A nutritive value index for forages. Journal of Animal Science, v.19, p.538554, 1960.

DETMAnN, E; QUEIROZ, A.C.; CECON, P.R.; et al. Consumo de fibra em detergente neutro por bovinos em confinamento. Revista Brasileira de Zootecnia, v.32, p.1763-1777, 2003 (supl.1).

GRINGS, E.E.; ROFFLER, R.E.; DEITELHOFF, D.P. Response of dairy cows in early lactation to additions of cottonseed meal in alfafa-based diets. Journal of Dairy Science, v.74, p.25802587, 1991 .

HALL, M.B. Neutral detergent-soluble carbohydrates nutritional relevance and analysis. (s.1.): Institute of Food Agricultural Sciences and University of Florida, 2000. 41p.

HEINRICHS, A.J.; ROGERS, G.W.; COOPER, J.B. Predicting body weight and wither height in Holstein heifers using body measurements. Journal of Dairy Science, v.75, p.3576-3581, 1992.

HOFFMAN, P.C. Optimum body size of Holstein replacement heifers. Journal of Animal Science, v.75, p.836-845, 1997.

JARDIM, V.R. Curso de bovinocultura. 4.ed. Campinas: Instituto Campineiro de Ensino Agrícola, 1973. 81p.

KOBAYASHI, K.; SALAM, M.U. Comparing simulated and measured values using mean squared deviation and its components. Agronomy Journal, v.92, p.345-352, 2000.

LANNA, D.P.D.; MORAIS, J.P.; BOIN, C. Desempenho e composição corporal de novilhas alimentadas com dois níveis de concentrado e bagaço de cana submetidos a diferentes processos de hidrólise. Revista Brasileira de Zootecnia, v.28, p.412-420, 1998.

LICITRA, G.; HERNANDEZ, T.M.; VAN SOEST, P.J. Standardization of procedures for nitrogen fractionation of ruminant feeds. Animal Feed Science and Technology, v.57, n.4, p.347-358, 1996.

MAESOOMI, S.M.; GHORBANI, G.R.; ALIKHANI, M. et al. Short communication: canola meal as a substitute for cottonseed meal in diet of midlactation holsteins. Journal of Dairy Science, v.89, p.1673-1677, 2006.

MAYER, D.G.; STUART, M.A.; SWAIN, A.J. Regression of realworld data on model output: an appropriate overall test of validity. Agricultural Systems, v.45, p.93-104, 1994.

MERTENS, R.R. Analysis of fiber in feeds and its uses in feed evaluation and ration formulation. In: SIMPÓSIO INTERNACIONAL DE RUMINANTES, 1992, Lavras. Anais... Lavras: Sociedade Brasileira de Zootecnia, 1992. p.1-32.

NATIONAL RESEARCH COUNCIL - NRC. Nutrient requirements of dairy cattle. 6.ed. Washington, D.C.: National Academy of Sciences, 1989. 158p.

NATIONAL RESEARCH COUNCIL - NRC. Nutrient requirements of dairy cattle. 7.ed. Washington, D.C.: National Academy Press, 2001. 381p.

OBARA, Y.; DELLOW, D.W.; NOLAN, J.V. The influence of energy-rich supplements on nitrogen kinetics in ruminants. In: TSUDA, T.; SASAKI, Y.; KAWASHIMA, R. (Eds.) 
Physiological aspects of digestion and metabolism in ruminants. New York: Academic Press, 1991. p.515-539.

OUSBOURN, D.F.; TERRY, R.A.; OUTEM, G.E. et al. The significance of a determination of cell walls as the rational bases for nutritive evaluation of forages. In: INTERNATIONAL GRASSLAND CONGRESS, 12., 1974, Moscou. Proceedings... Moscou: 1974. v.3, p.374.

PINA, D.S.; VALADARES FILHO, S.C.; VALADARES, R.F.D. et al. Consumo e digestibilidade aparente total dos nutrientes, produção e composição do leite de vacas alimentadas com dietas contendo diferentes fontes de proteína. Revista Brasileira de Zootecnia, v.35, n.4, p.1543-1551, 2006.

QUIGLEY, J.D.; JAMES, R.E.; McGILLIARD, M.L. Dry matter intake in dairy heifers. 1. Factors affecting intake of heifers under intensive management. Journal of Dairy Science, v.69, p.2855-2862, 1986a.

QUIGLEY, J.D.; JAMES, R.E.; McGILLIARD, M.L. Dry matter intake in dairy heifers. 2. Equations to predict intake of heifers under intensive management. Journal of Dairy Science, v.69, p.2863-2867, 1986b.

REIS, G.L.; ALBUQUERQUE, F.H.M.R.; TEODORO, R.L. et al. Estimativa do peso vivo de novilhas mestiças leiteiras a partir de medidas corporais. In: SIMPÓSIO DA SOCIEDADE BRASILEIRA
DE MELhORAMENTO ANIMAL, 2004, Pirassununga. Anais.. Pirassununga: USP, 2004. p.154.

SEJRSEN, K.; PURUP, S. Influence of prepuberal feeding level on milk yeld potential of dairy heifers. A review. Journal of Animal Science, v.75, p.828-835, 1997.

SILVA, D.J.; QUEIROZ, A.C. Análise de alimentos: métodos químicos e biológicos. 3.ed. Viçosa, MG: UFV, 2002. 235p.

SNIFFEN, C.J.; O'CONNOR J.D.; VAN SOEST, P.J. et al. A net carbohydrate and protein system for evaluating cattle diets: carbohydrate and protein availability. Journal of Animal Science, v.70, p.3562-3577, 1992.

UNIVERSIDADE FEDERAL DE VIÇOSA - UFV. SAEG - Sistema de análises estatísticas e genéticas. Versão 7.1. Viçosa, MG, 1997. 150p. (Manual do usuário).

VALADARES FILHO, S.C.; PAULINO, P.V.R.; MAGALHÃES, K.A. Exigências nutricionais de zebuínos e tabelas de composição de alimentos BR-corte. 1.ed. Viçosa, MG: Universidade Federal de Viçosa, 2006. 142p.

VAN SOEST, P.J. Nutricional ecology of the ruminant. 2.ed. Ithaca: Cornell University Press, 1994. 476p.

ZIN, R.A.; MONTANO, M.; ALVAREZ, E. et al. Feeding value of cottonseed meal for feedlot cattle. Journal of Animal Science, v.75, p.2317-2322, 1997. 